\title{
Bacterial Strain Isolated from High-Salt Environments Can Produce Large Amounts of New Polyhydroxyalkanoate (PHA)
}

\author{
Ahmad Gholami ${ }^{1,2}$, Younes Ghasemi ${ }^{2}$, Aboozar Kazemi' ${ }^{2}$, Seyyedeh Narjes Abootalebi ${ }^{3}$, \\ Cambyz Irajie $^{4}$, Aida Ireji ${ }^{5}$, Navid Omidifar ${ }^{1}$, Milad Mohkam $^{6 *}$ \\ Biotechnology Research Center, Shiraz University of Medical Sciences, Shiraz, Iran \\ ${ }^{2}$ Department of Pharmaceutical Biotechnology, School of Pharmacy, Shiraz University of Medical Sciences, Shiraz, Iran \\ ${ }^{3}$ Devision of Intensive Care Unit, Department of Pediatrics, School of Medicine, Shiraz University of Medical Sciences, Shiraz, Iran \\ ${ }^{4}$ Department of Medical Biotechnology, School of Advanced Technologies in Medicine, Shiraz University of Medical Sciences, Shiraz, Iran \\ ${ }^{5}$ Medicinal and natural products chemistry Research Center, Shiraz University of Medical Sciences, Shiraz, Iran \\ ${ }^{6}$ Pharmaceutical Sciences Research Center, Shiraz University of Medical Sciences, Shiraz, Iran
}

\begin{abstract}
Since the major problem connected to the industrial production of Polyhydroxyalkanoates (PHAs) is their high production price, this study was performed to inspect the new potential bacterial species for industrial PHA production. The bacterial samples were collected during a screening program from Pink Salt Lake as an extreme environment in the south of Iran, Fars province. The PHA-producing bacteria were isolated. Then further studies on different morphological, cultural, and physiological characteristics of isolates were performed. Among the isolated microorganisms in this study, 18 of 143 bacteria were selected as PHA-producer microorganisms to be studied for analysis along with a partial sequence of the 16S rRNA gene. This study introduces two bacteria; Bacillus endophyticus BCCS 011 and Lysobacter sp. BCCS 052 as new potential PHA producer that has not been reported previously. They could be an ideal option for cheaper PHAs production.
\end{abstract}

Keywords: Polyhydroxyalkanoate (PHA), Bacillus, Lysobacter, 16S rRNA, Extreme environment

\section{Introduction}

Polyhydroxyalkanoates (PHA), a family of biopolymers with diverse structures, are polyoxoesters of hydroxy alkanoic acids which are synthesized by various bacteria to overcome environmental stress (1). Originally, they are accumulated as carbon and energy reserves by a variety of bacterial species under nutrient (Phosphorus, Nitrogen, or Sulfur) depleted circumstances with excess carbon (2). Based on the monomer structures, PHA are divided into short-chain-length (SCL) PHA commonly consisting of 3-hydroxypropionate (3HP), 3hydroxybutyrate (3HB) and 3 hydroxyvalerate (3HV); medium-chain-length (MCL) PHA containing 3hydroxyhexanoate (3HHx), 3 hydroxyheptanoate (3HHp) to 3hydroxytetradecanoate (3HTD) $(3,4)$. Many bacteria are capable of producing PHAs in activated sludge, in high seas, and extreme environments (5). PHAs are biocompatible, biodegradable, and environmentally friendly thermoplastics as compared to petroleum-based plastics that are harmful wastes and take several years to degrade completely $(6,7)$. Because of increasing global environmental concerns associated with discarded petrochemical-based plastics (8-12), several studies have been conducted on the development of an appropriate ecofriendly material that can substitute at least some of the commodity plastics (13-17). PHAs properties like conventional plastics (especially polypropylene) have versatile plasticable properties and are produced as high molecular mass polymers in bacteria (18). Therefore, they have a wide range of applications, such as in the packaging industry, pharmacy, medicine, agriculture, and food industry (19). As a result, the fabrication of biodegradable polymers such as PHAs from renewable sources is the need of the today, in the face of these environmental facts.

Production and marketing of PHAs have been restricted in two ways. The first cope with the ability of bacteria in accumulation of the polymer, while more than 300 bacterial species have been found in PHA accumulation, but accumulation levels in many of them is very low (20). On the other hand, species such as Alcaligenes latus, Ralstonia eutropha (formerly known as Alcaligenes eutrophus), Pseudomonas putida, Pseudomonas oleovorans, recombinant Escherichia coli and Azotobacter vinelandii have been extensively investigated $(21,22)$. The second aspect, which has restricted PHA production and marketing, is associated with the high costs of the substrate (mainly carbon source) as compared to those of petrochemical origin (23). New strains, using economic substrates along with having a high accumulation proportion, must thus be isolated to solve these problems mentioned above. Interest has been a focus on Grampositive bacteria such as the genera Bacillus, where this bacterium has chemoorganotrophic features(24-28), secretion of a large number of amylases and proteases (29) and lack lipopolysaccharide (LPS) (30). These properties of Bacillus

Corresponding author: Milad Mohkam' Pharmaceutical Sciences Research Center, Shiraz University of Medical Sciences, Shiraz, Iran. Tel.: +98 713242 6729; Fax: +98 7132426729 and E-mail: miladmohkam@ gmail.com 
spp. are of interest for exploring the possibility of utilizing different agricultural raw materials as a carbon source for the fabrication of various metabolites (24). Furthermore, the genera of Bacillus are suitable model systems for the heterologous expression of foreign genes related to PHA manufacturing and numerous fine chemicals (31). In the present study, PHB producing bacteria from a salty lake (Pink Lake, Shiraz, Iran) were isolated, identified, and characterized using morphological, biochemical, and molecular methods. To our best knowledge, this is the first report of Bacillus endophyticus along with Lysobacter sp., and Pantoea sp. as PHA producers that can be industrially exploited for bioplastics fabrication.

\section{Materials and Methods \\ 1.1 Sample collection}

Bacterial isolates were obtained from a salty lake "Pink Lake" Fars province, in the south of Iran. Briefly, liquid samples were collected and transferred in sterile tubes at the ice. The samples were then serially diluted with sterile distilled water, and then $200 \mu \mathrm{L}$ of the dilution was spread on a sterile Nutrient Agar (NA) plates. The plates were incubated at $\mathrm{pH}=7$ and $30{ }^{\circ} \mathrm{C}$ for two days. Various colonies of different morphology, including color, form, and edge appearance, were individually picked and subcultured 3-4 times on nutrient agar plates. Pure bacterial isolates were achieved by subculturing individual colonies several times on a fresh NA medium to gain single colonies. Agar slants of these colonies were kept at $4{ }^{\circ} \mathrm{C}$ for one month

\subsection{Screening the PHA-producing bacteria}

All the bacterial isolates were qualitatively examined for PHA production by Sudan Black B dye to detect the existence of lipid granules in the bacteria (32). A positively-stained isolate was considered a potential PHA producer and cultured in the modified E2 medium, a nitrogen-limiting medium containing $2 \%(\mathrm{w} / \mathrm{v})$ glucose $(20 \mathrm{~g} / \mathrm{l}$ of Glucose), $0.9 \mathrm{gr} / \mathrm{l}$ of $\mathrm{NH}_{4} \mathrm{Cl}, 0.9 \mathrm{gr} / 1$ of $\mathrm{NaCl}, 5.22 \mathrm{gr} / 1$ of $\mathrm{K}_{2} \mathrm{HPO}_{4}, 3.7 \mathrm{gr} / 1$ of $\mathrm{KH}_{2} \mathrm{PO}_{4}, 0.246 \mathrm{gr} / \mathrm{l}$ of $\mathrm{MgSO}_{4} .7 \mathrm{H}_{2} \mathrm{O}$, and $1 \mathrm{ml}$ of $\mathrm{MT}$ microelement (1 liter of MT stock contains $2.78 \mathrm{gr}$ of $\mathrm{FeSO}_{4} .7 \mathrm{H}_{2} \mathrm{O}, 1.98 \mathrm{gr}$ of $\mathrm{MnCl}_{2} .4 \mathrm{H}_{2} \mathrm{O}, 2.81 \mathrm{gr}$ of $\mathrm{CoCl}_{2} .6 \mathrm{H}_{2} \mathrm{O}$, $1.47 \mathrm{gr}$ of $\mathrm{CaCl}_{2}, 0.17 \mathrm{gr}$ of $\mathrm{CuSO}_{4} .5 \mathrm{H}_{2} \mathrm{O}$ and $0.29 \mathrm{gr}$ of $\mathrm{ZnSO}_{4} .7 \mathrm{H}_{2} \mathrm{O}$ ) at $37^{\circ} \mathrm{C}$ for $72 \mathrm{~h}$. Then all the isolates were stained by Nile blue a dye to confirm the PHA production.

\subsection{Identification of Bacterial isolates}

The PHA-positive bacterial isolates were identified according to conventional biochemical tests and by partially sequencing the ribosomal 16s RNA gene. Total genomic DNA was extracted according to Gholami et al. and was used as a Chromosomal DNA template for the amplification of the $16 \mathrm{~s}$ RNA gene (33). The following oligonucleotide sequences 5'ACGGGCGGTGTGTAC -3' were used as forward, and 5'CAGCCGCGGTAATAC-3' reverse primers. The PCR products were purified and then sequenced by CinnaGen Company (Tehran, Iran). The resulting 16S rRNA gene sequences were aligned and compared to the nucleotide sequences of some known microorganisms in the GenBank database of the National Center for Biotechnology Information by using the Basic Local Alignment Search Tool (BLAST). The nucleotide sequences of 16S rRNA genes were published to GenBank under the accession numbers, as shown in table1. Then the PHA extracted from all the PHA positive isolates were analyzed by an spectroscopic methods, FT-IR.

\subsection{FT-IR spectroscopy}

The infrared (IR) spectrum was recorded using Bruker, Vertex 70, FTIR spectrometer (34). The extracted PHA was dissolved in chloroform, and the unfiltered solution was cast onto $\mathrm{NaCl}$ crystal.

\section{Results and discussion}

In this study, a total of 143 bacterial isolates were examined for isolation of PHA-producing bacteria from a salty lake (Pink Lake). This seasonal lake also locally known as Maharloo is located in the $27.0 \mathrm{~km}$ southeast of Shiraz, Iran, which is full of potassium and other salts and looks pink (Fig. 1).

Of these isolates, 21 of them were positive for PHA using Sudan Black B and then confirmed by Nile Blue A. Sudan Black B was used as the first-line screening for PHAaccumulating bacteria when they were cultured in an unbalanced growth medium. It was assumed that the negatively stained of isolates with Sudan Black B did not form lipid granules and thus also did not produce PHA due to the lipidic feature of polyester. Sudan black B stains PHA nonspecifically as well as for other lipid bodies. In contrast, Nile Blue A is more specific than Sudan black B for PHA detection. Therefore, Nile Blue A was used for confirmation of PHAaccumulating bacteria. The bacterial flora is categorized into two groups, according to their Gram's reaction. In general, the Gram-positive bacteria tended to dominate the salty lake, nearly $66.67 \%$ of the total 21 PHA-producing isolates showed Gram-positive character. The result of PCR blasted with other sequenced bacteria in NCBI showed a similarity of more than $95 \%$ to the $16 \mathrm{~S}$ rRNA of other bacteria. Various microbiological and biochemical tests were carried out as a means for the identification of native strains (Table 1). Among 21 of PHA-producing isolates, 13 isolates were belonged to Bacillus and one isolate to Halobacterium genera along with other Gram-negative bacteria (Table 2). These isolates (Bacillus spp. and Halobacterium) showed strong growth in $10 \%(w / v)$ salt concentration suggesting that they could tolerate relatively salt concentration, which is consistent with the natural condition of this salty lake. These bacteria tend to accumulate PHA, which is commonly consumed by the bacterium itself when the growth circumstances are unfavorable. The PHA-positive isolates opted after Nile blue A staining and then grown in an E2 broth medium containing 2\% $(\mathrm{w} / \mathrm{v})$ glucose in 100-ml flasks, and were employed to extract PHA after two days of incubation on a rotary shaker. The PHA from the isolates was extracted by the chloroform method, developed by Vizcaino-Caston et al. (35). The concentration of PHA in the E2 medium and PHA\% of cell dry weight along with cell dry weight achieved for various positively stained isolates are depicted in Table 2. These isolates produced PHA from 0.031 to $0.34 \mathrm{~g} / \mathrm{l}$, amounting to about $2.16-23.13 \%$ PHA of cell dry weight (Table 2). 


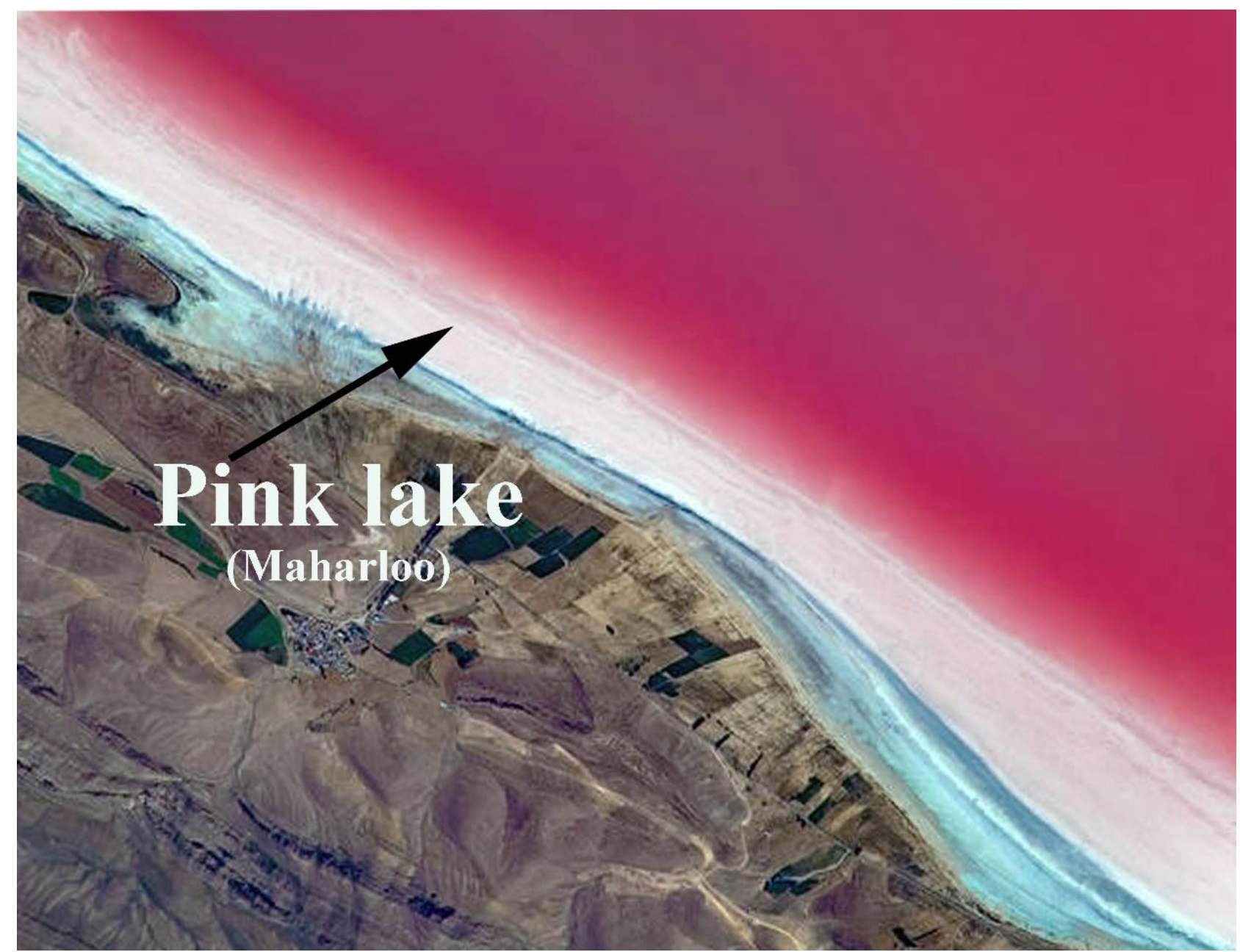

Figure 1: Satellite image of salty Pink Lake

Table 1: The morphological and biochemical traits used for classification of 21 selected PHA-producer isolates

\begin{tabular}{cc}
\hline Morphology & Gelatinase production \\
Cell shape & Catalase production \\
Cell size & Oxidase production \\
Motility & Lipase production \\
Gram staining & Hippurate hydrolysis \\
Endospore & Esculin hydrolysis \\
Spore shape & Alucose \\
Spore position & Galactose \\
Colony shape & Fructose \\
Optimum pH & Mannitol \\
Optimum temperature & Maltose \\
Growth on nutrient agar & Sucrose \\
Growth on McConkey agar & Utilization of \\
Growth on Eosin methylene blue agar & Succinate \\
Growth at 5,20 and $50^{\circ} \mathrm{C}$ & Citrate \\
Growth in NaCl $2.5-7.0 \%$ & Resistance to antibiotics \\
Urease production & Erythromycin \\
Nitrate reduction & Neomycin \\
Voges-Proskauer & Novabiocin \\
Arginine hydrolysis & Tetracycline \\
Casein hydrolysis & Kanamycin \\
Lecithinase production & Chloramphenicol \\
HCN production & Ampicillin \\
& Tetracycline \\
\hline
\end{tabular}


Table 2: The amount $(\mathrm{mg} / \mathrm{ml})$ and the weight yield (w \%) of PHA of production, the accession numbers and the concentration of obtained from the screened bacteria which were isolated from Maharlu Lake.

\begin{tabular}{|c|c|c|c|}
\hline Bacteria & Dry cell weight $(\mathrm{gr} / \mathrm{l})$ & PHA.con (gr/l) & $\%$ PHA (CDW) \\
\hline Bacillus endophyticus BCCS 011 & 1.36 & 0.24 & 17.64 \\
\hline Bacillus sp. BCCS 060 & 0.786 & 0.066 & 8.39 \\
\hline Bacillus subtilis BCCS 028 & 0.926 & 0.08 & 8.63 \\
\hline Bacillus subtilis BCCS 033 & 3.24 & 0.126 & 3.9 \\
\hline Bacillus sp. BCCS 036 & 0.926 & 0.128 & 13.82 \\
\hline Halobacterium sp. BCCS 030 & 0.973 & 0.09 & 9.4 \\
\hline Bacillus subtilis BCCS 031 & 1.4 & 0.033 & 2.3 \\
\hline Bacillus endophyticus BCCS 024 & 1.36 & 0.034 & 2.5 \\
\hline Bacillus pumilus BCCS 002 & 0.686 & 0.10 & 15.4 \\
\hline Bacillus subtilis BCCS 005 & 1.03 & 0.04 & 4 \\
\hline Bacillus subtilis BCCS 012 & 0.66 & 0.085 & 13 \\
\hline Pantoea sp. BCCS 053 & 0.613 & 0.05 & 8.4 \\
\hline Escherichia coli BCCS 054 & 1.14 & 0.045 & 3.93 \\
\hline Escherichia coli BCCS 055 & 0.933 & 0.106 & 11.4 \\
\hline Aeromonas sp. BCCS 056 & 2.166 & 0.038 & 1.8 \\
\hline Bacillus sp. BCCS 057 & 0.793 & 0.05 & 6.4 \\
\hline Aeromonas sp. BCCS 058 & 1.866 & 0.07 & 4 \\
\hline Bacillus sp. BCCS 059 & 1.286 & 0.113 & 8.8 \\
\hline Bacillus sp. BCCS 061 & 1.46 & 0.026 & 1.8 \\
\hline Lysobacter sp. BCCS 052 & 1.466 & 0.046 & 3.2 \\
\hline
\end{tabular}

FTIR spectroscopy of the polymer producing bacteria was investigated along with Poly $(R)$-3-hydroxybutyric acid (PHB) prepared from Sigma-Aldrich (cat no: 363502). The polymer extracted illustrated the intense absorption characteristic for ester carbonyl $(\mathrm{C}=\mathrm{O})$ stretching groups at 1720, 2325 and 2985 $\mathrm{cm}^{-1}$ corresponding to the $-\mathrm{CH}$ group in comparison with the PHB (Fig. 2).

An important finding was that all Bacillus spp could able to produce a high amount of PHA in comparison to other bacterial species. To our knowledge, this study introduces a new species of Bacillus named Bacillus endophyticus that has a high ability to produce PHA (23.13\% of CDW) as compared to other isolates. The Bacillus spp. are critical industrial bacteria for the production of such enzymes and also for PHAs production. The properties, including lack of lipopolysaccharides (LPS) and the ability to consume a wide range of cheap carbon sources, made this bacterium a suitable candidate for the production of PHAs, especially for medical implant purposes (33). Moreover, recovery of approximately 70 to $90 \%$ of bacterial dry biomass as PHA production is potentially enough for determining an economically feasible process (2).Most interestingly, this research also identifies a novel bacterium Lysobacter, which has not been reported as a PHA producer so far. This bacterium is considered a rich source for the fabrication of novel antibiotics, such as macrocyclic lactams, $\beta$-lactams containing substituted side chains and macrocyclic peptides (36). The ease of genetic manipulation and able to occupy a wide range of ecological niches, including a broad range of extreme environments, provides this bacterium an ideal candidate for PHA production (37). Therefore, such studies are needed for the development of these new potential strains for commercial PHA production.

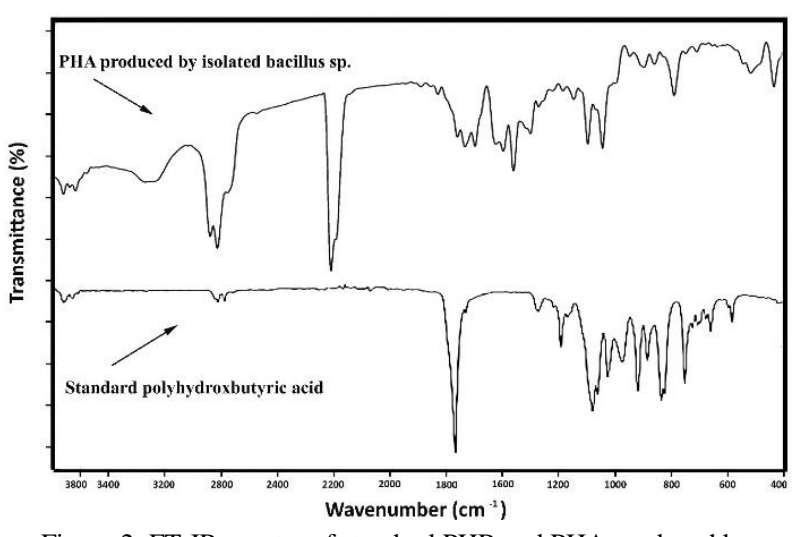

Figure 2: FT-IR spectra of standard PHB and PHA produced by isolated bacterial strain

\section{Conclusion}

In conclusion, different bacterial strains were isolated from an extremely salty lake and screened for polyhydroxyalkanoate production, and bacterial isolates were identified and characterized using morphological, biochemical, and molecular methods in this study. Within this extremely halophilic environment, most PHA-producing strains were from genus bacillus. Besides, other strains such as Pantoea sp., Halobacterium sp., and Lysobacter sp. have a high potential for the conversion of carbohydrates into PHB. Among the isolated strains, Bacillus endophyticus was able to produce the highest amount of polyhydroxy butyrate $(23.13 \%$ of the cell dry mass, which is very important from an industrial point of view. Presently, the selected microorganisms are further considered to enhance the production of polyhydroxyalkanoates by the optimization of the process factors. In order for the industrial 
production of this environmentally valuable product, it is critical to produce more cost-effectively and to achieve greater competitiveness with similar petroleum products that severely pollute the environment.

\section{Acknowledgment}

This work was supported by the Research Council of Shiraz University of Medical Sciences, Shiraz, Iran.

\section{Ethical issue}

Authors are aware of, and comply with, best practice in publication ethics specifically with regard to authorship (avoidance of guest authorship), dual submission, manipulation of figures, competing interests and compliance with policies on research ethics. Authors adhere to publication requirements that submitted work is original and has not been published elsewhere in any language.

\section{Competing interests}

The authors declare that there is no conflict of interest that would prejudice the impartiality of this scientific work.

\section{Authors' contribution}

All authors of this study have a complete contribution for data collection, data analyses and manuscript writing.

\section{References}

1. Gholami A, Mohkam M, Rasoul-Amini S, Ghasemi Y. Industrial production of polyhydroxyalkanoates by bacteria: opportunities and challenges. Minerva Biotecnologica. 2016;28(1):59-74.

2. Kourmentza C, Plácido J, Venetsaneas N, Burniol-Figols A, Varrone C, Gavala HN, et al. Recent Advances and Challenges towards Sustainable Polyhydroxyalkanoate (PHA) Production. Bioengineering (Basel). 2017;4(2):55.

3. Cha D, Ha HS, Lee SK. Metabolic engineering of Pseudomonas putida for the production of various types of short-chain-length polyhydroxyalkanoates from levulinic acid. Bioresource Technology. 2020;309:123332.

4. Zheng Y, Chen J-C, Ma Y-M, Chen G-Q. Engineering biosynthesis of polyhydroxyalkanoates (PHA) for diversity and cost reduction. Metabolic engineering. 2020;58:82-93.

5. Pang H, Ma W, He J, Pan X, Ma Y, Guo D, et al. Hydrolase activity and microbial community dynamic shift related to the lack in multivalent cations during cation exchange resin-enhanced anaerobic fermentation of waste activated sludge. Journal of Hazardous Materials. 2020:122930.

6. Zhong Y, Godwin P, Jin Y, Xiao H. Biodegradable polymers and green-based antimicrobial packaging materials: A mini-review. Advanced Industrial and Engineering Polymer Research. 2020;3(1):27-35.

7. Shrivastav A, Mishra SK, Shethia B, Pancha I, Jain D, Mishra S. Isolation of promising bacterial strains from soil and marine environment for polyhydroxyalkanoates (PHAs) production utilizing Jatropha biodiesel byproduct. International Journal of Biological Macromolecules. 2010;47(2):283-7.

8. Mousavi S, Aghili A, Hashemi S, Goudarzian N, Bakhoda Z, Baseri S. Improved morphology and properties of nanocomposites, linear low density polyethylene, ethylene-co-vinyl acetate and nano clay particles by electron beam. Polymers from Renewable Resources. 2016;7(4):135-53.

9. Mousavi S, Hashemi S, Amani A, Moujodi F, Hamedfateh A, Zarei M. Modification of polypropylene-starch blend by eggshell nano-particle, EVA and maleic anhydride to improve biodegradability and thermal properties. Int $\mathrm{J}$ Chem Sci. 2018;15:225.

10. Mousavi SM, Hashemi SA, Amani AM, Saed H, Jahandideh S, Mojoudi F. Polyethylene terephthalate/acryl butadiene styrene copolymer incorporated with oak shell, potassium sorbate and egg shell nanoparticles for food packaging applications: control of bacteria growth, physical and mechanical properties. Polymers from Renewable Resources. 2017;8(4):177-96

11. Mousavi SM, Hashemi SA, Jahandideh S, Baseri S, Zarei M, Azadi S. Modification of phenol novolac epoxy resin and unsaturated polyester using sasobit and silica nanoparticles. Polymers from Renewable Resources. 2017;8(3):117-32.

12. Mousavi SM, Zarei M, Hashemi SA, Lai CW, Bahrani S. K-Ion Battery Practical Application Toward Grid-Energy Storage. Potassium-ion Batteries: Materials and Applications. 2020:43.

13. Bahrani S, Hashemi SA, Mousavi SM, Azhdari R. Zinc-based metal-organic frameworks as nontoxic and biodegradable platforms for biomedical applications: review study. Drug metabolism reviews. 2019;51(3):356-77.

14. Goudarzian N, Hashemi S, Mirjalili M. Unsaturated polyester resins modified with cresol novolac epoxy and silica nanoparticles: processing and mechanical properties. Int $\mathrm{J}$ Chem Pet Sci. 2016;5(1):13-26

15. Hashemi SA, Mousavi SM, Ramakrishna S. Effective removal of mercury, arsenic and lead from aqueous media using PolyanilineFe3O4-silver diethyldithiocarbamate nanostructures. Journal of Cleaner Production. 2019;239:118023.

16. Mousavi S, Zarei M, Hashemi S. Polydopamine for biomedica application and drug delivery system. Med Chem (Los Angeles). 2018;8:218-29.

17. Mousavi SM, Hashemi SA, Salahi S, Hosseini M, Amani AM, Babapoor A. Development of clay nanoparticles toward bio and medical applications. Current Topics in the Utilization of Clay in Industrial and Medical Applications. 2018;9:167.

18. Sharma L, Srivastava JK, Singh AK. Biodegradable polyhydroxyalkanoate thermoplastics substituting xenobiotic plastics: a way forward for sustainable environment. Plant Responses to Xenobiotics: Springer; 2016. p. 317-46.

19. Battista F, Frison N, Pavan P, Cavinato C, Gottardo M, Fatone F, et al. Food wastes and sewage sludge as feedstock for an urban biorefinery producing biofuels and added-value bioproducts. Journal of Chemical Technology \& Biotechnology. 2020;95(2):328-38.

20. Możejko-Ciesielska J, Kiewisz R. Bacterial polyhydroxyalkanoates: still fabulous? Microbiological Research. 2016;192:271-82.

21. Mohapatra S, Mohanta P, Sarkar B, Daware A, Kumar C, Samantaray D. Production of polyhydroxyalkanoates (PHAs) by Bacillus strain isolated from waste water and its biochemical characterization. Proceedings of the National Academy of Sciences, India Section B: Biological Sciences. 2017;87(2):459 66.

22. Gholami A, Shahin S, Mohkam M, Nezafat N, Ghasemi Y Cloning, Characterization and Bioinformatics Analysis of Novel Cytosine Deaminase from Escherichia coli AGH09. International Journal of Peptide Research and Therapeutics. 2015;21(3):365-74

23. Arumugam A, Anudakshaini T, Shruthi R, Jeyavishnu K, Harini SS, Sharad J. Low-cost production of PHA using cashew apple (Anacardium occidentale L.) juice as potential substrate: optimization and characterization. Biomass Conversion and Biorefinery. 2019:1-12.

24. Mohkam M, Rasoul-Amini S, Shokri D, Berenjian A, Rahimi F Sadraeian $\mathrm{M}$, et al. Characterization and in vitro probiotic assessment of potential indigenous Bacillus strains isolated from soil rhizosphere. Minerva Biotecnologica. 2016;28(1):19-28.

25. Mousavi SM, Hashemi SA, Zarei M, Bahrani S, Savardashtaki A, Esmaeili $\mathrm{H}$, et al. Data on cytotoxic and antibacterial activity of synthesized Fe3O4 nanoparticles using Malva sylvestris. Data in brief. 2020;28:104929.

26. Mousavi SM, Zarei M, Hashemi SA, Babapoor A, Amani AM. A conceptual review of rhodanine: current applications of antiviral drugs, anticancer and antimicrobial activities. Artificial cells, nanomedicine, and biotechnology. 2019;47(1):1132-48

27. Mousavi SM, Zarei M, Hashemi SA, Ramakrishna S, Chiang W$\mathrm{H}$, Lai CW, et al. Gold nanostars-diagnosis, bioimaging and biomedical applications. Drug Metabolism Reviews. 2020;52(2):299-318

28. Tech JET. Investigating the Activity of Antioxidants Activities Content in Apiaceae and to Study Antimicrobial and Insecticidal Activity of Antioxidant by using SPME Fiber Assembly 
Carboxen/Polydimethylsiloxane (CAR/PDMS). Journal of Environmental Treatment Techniques. 2020;8(1):214-24.

29. Lorpour M, Kazemi A, Gholami A, Safari A, Ghasemi Y. Isolation and phylogenetic analysis of some lipase producing bacteria from a saline lake. Journal of Pure and Applied Microbiology. 2015;9(1):497-502.

30. Kazemi A, Lorpour M, Gholami A, Solhjoo K, Ghasemi Y. High level amylase production by Pseudomonas stutzeri ML-18; isolation, identification and media optimization in a fermentation system using Response Surface Methodology (RSM). Journal of Pure and Applied Microbiology. 2015; 9(Special Edition 2):12733.

31. Mohapatra S, Maity S, Dash HR, Das S, Pattnaik S, Rath CC, et al. Bacillus and biopolymer: Prospects and challenges. Biochemistry and biophysics reports. 2017;12:206-13.

32. Ebrahimi N, Gharibi S, Ghoshoon MB, Karimi Z, Gholami A, Nezafat N, et al. Selective Isolation and Identification of Arginine Degrading Bacteria; the Optimized Arginine Deaminase Production by Enterobacter sp. sgn1 as a New Source of This Potentially Anti-Tumor Enzyme. Journal of Applied Pharmaceutical Science. 2016;6(09):093-101.

33. Abootalebi SN, Saeed A, Gholami A, Mohkam M, Kazemi A, Nezafat N, et al. Screening, Characterization and Production of
Thermostable Alpha-Amylase Produced by a Novel Thermophilic Bacillus megaterium Isolated from Pediatric Intensive Care Unit Journal of Environmental Treatment Techniques. 2020;8(3):95260 .

34. Gholami A, Rasoul-Amini S, Ebrahiminezhad A, Abootalebi N, Niroumand U, Ebrahimi N, et al. Magnetic properties and antimicrobial effect of amino and lipoamino acid coated iron oxide nanoparticles. Minerva Biotecnologica. 2016;28(4):177-86.

35. Vizcaino-Caston I, Kelly CA, Fitzgerald AV, Leeke GA, Jenkins M, Overton TW. Development of a rapid method to isolate polyhydroxyalkanoates from bacteria for screening studies. Journal of bioscience and bioengineering. 2016;121(1):101-4.

36. Boto A, Pérez de la Lastra JM, González CC. The road from hostdefense peptides to a new generation of antimicrobial drugs. Molecules. 2018;23(2):311.

37. Wang $\mathrm{C}, \mathrm{Xu} \mathrm{H}$, Zhang $\mathrm{Y}$, Wu S, Chen D, Qian $\mathrm{G}$, et al. Optimization of culture conditions for promoting heat-stable antifungal factor production level in Lysobacter enzymogenes. FEMS Microbiology Letters. 2019;366(17):fnz007. 